\title{
Flora of Singapore precursors, 28: Taxonomic and nomenclatural clarification of Kadsura species (Schisandraceae) in Singapore
}

\author{
J. Chen ${ }^{1}$, X.Y. Ng${ }^{2}$, R.C.J. Lim², H.K. Lua ${ }^{3}$ \& R.M.K. Saunders ${ }^{4}$ \\ ${ }^{1}$ Singapore Botanic Gardens, National Parks Board, \\ 1 Cluny Road, 259569 Singapore \\ junhao_chen@nparks.gov.sg \\ ${ }^{2}$ Native Plant Centre, Horticulture and Community Gardening Division, \\ National Parks Board, 100K Pasir Panjang Road, 118526 Singapore \\ ${ }^{3}$ National Biodiversity Centre, National Parks Board, \\ 1 Cluny Road, 259569 Singapore \\ ${ }^{4}$ Division of Ecology \& Biodiversity, School of Biological Sciences, \\ The University of Hong Kong, Pokfulam Road, Hong Kong, China
}

\begin{abstract}
Recent taxonomic and floristic accounts list Kadsura scandens (Blume) Blume as the sole native Kadsura species in Singapore. However, these works have overlooked Ridley's earlier documentation of another species, Kadsura verrucosa (Gagnep.) A.C.Sm., which was recorded under the misapplied name $K$. cauliflora. The reduction of Kadsura cauliflora to a synonym of $K$. scandens led to the uncritical acceptance of a single Kadsura species in Singapore. The confusion between Kadsura scandens and the morphologically similar $K$. verrucosa may be partly attributed to the demonstrably ambiguous lectotype of $K$. scandens. An epitype is therefore designated for Kadsura scandens. Key differences between the two Kadsura species and brief propagation notes are provided here.
\end{abstract}

Keywords. Epitype, Kadsura cauliflora, Kadsura scandens, Kadsura verrucosa, misapplied name

\section{Introduction}

Kadsura Kaempf. ex Juss. (Schisandraceae) is a genus of twining lianas, with a centre of diversity in southern China and West Malesia, extending from Sri Lanka and eastern India in the west, to Japan in the north-east, and to Java, Sulawesi and the Moluccas in the south-east (Saunders, 1998a). The most recent monograph of the genus recognises 16 species (Saunders, 1998a). However, with the recent resurrection of Kadsura matsudae Hayata (formerly a synonym of $K$. japonica (L.) Dunal) from the Ryukyu Islands (Japan) and Taiwan (Suetsugu et al., 2017), the genus now comprises 17 species. As a member of the basal angiosperms (order Austrobaileyales), Kadsura exhibits several plesiomorphic traits such as an elongated floral axis with numerous spirally arranged organs, a perianth comprising tepals that lack distinction between sepals and petals, and poorly differentiated carpels, without true styles or stigmas (Saunders, 1998a). However, unlike most basal angiosperms, Kadsura is monoecious 
with unisexual flowers (Saunders, 1998a). The male flowers possess highly variable androecial morphology on which the sectional classification of the genus (Smith, 1947) is predicated. The fruit of Kadsura comprises many sessile berries that are appressed into a spherical or ellipsoidal mass, except K. verrucosa (Gagnep.) A.C.Sm. which has berries that are borne on short stipes derived from the receptacle (Saunders, 1998a). Because each berry is derived from a single carpel, the fruitlets are also referred to as apocarps (Saunders, 1998a). The closely related genus Schisandra is primarily distinguished from Kadsura in possessing apocarps on a highly elongated receptacle, apart from other subtler differences in androecial and pollen morphology (Saunders, 2000).

Ridley (1900) listed two Kadsura species ( $K$. cauliflora Blume from the Gardens Jungle, Bukit Timah and Kranji, and K. scandens (Blume) Blume from Bukit Timah and Bajau, then classified under Magnoliaceae) in his Flora of Singapore, representing the first record of the genus in Singapore. Subsequently, in his Flora of the Malay Peninsula, Ridley (1922) recorded Kadsura scandens from Singapore (no precise locality stated) and $K$. cauliflora from the Gardens Jungle. Noting the lack of remarkable differences between Kadsura cauliflora and K. scandens and the fact that the types of both species are from Java, Smith (1947) reduced $K$. cauliflora to a synonym of $K$. scandens. This synonymy was espoused by Keng (1990), who listed Kadsura scandens as the sole species in Singapore but noted "a small-leaved form formerly called K. cauliflora". The monograph of the genus (Saunders, 1998a) likewise accepted the synonymy but revealed that the name Kadsura cauliflora has been misapplied to K. verrucosa by previous authors (King, 1889, 1891; Ridley, 1922). The misapplication of the name is evident from the description "Carpels on pedicels $.5 \mathrm{in}$. long" in the aforementioned publications and from an illustration of the stipitate apocarps (King, 1891: pl. 72) that are only known in Kadsura verrucosa. Although this implies that Ridley's record of Kadsura cauliflora in Singapore actually indicates the occurrence of $K$. verrucosa, the monograph of Kadsura (Saunders, 1998a) does not record K. verrucosa for Singapore. Both the monograph (Saunders, 1998a) and the Schisandraceae account of the angiosperm flora of Singapore (Saunders, 1998b) clearly indicate Kadsura scandens as the only native species of the family in Singapore. Various checklists of the vascular plants of Singapore, including the most recent one by Chong et al. (2009) also only list a single Kadsura species, viz. K. scandens.

Several factors have led to the confusion between Kadsura scandens and $K$. verrucosa. The leaf morphology of the two species is highly similar and previous treatments have provided definitive distinction only based on fruit morphology. Saunders (1998a) suggested that the more frequent expression of cauliflory in Kadsura verrucosa and the superficial indication of this in the specific epithet of $K$. cauliflora may have resulted in the misapplication of names. Nevertheless, this conundrum may in part stem from the ambiguous type material of Kadsura scandens. The existing lectotype is sterile and its adaxial leaf intercostal venation (the sole vegetative character previously used to distinguish the two species) is somewhat more similar to Kadsura verrucosa than to $K$. scandens. We have therefore designated an epitype with diagnostic fruit characters to support the sterile lectotype, clarifying the application of 
the name Kadsura scandens. This paper also reports additional differences in the male and female flowers that have been uncovered in recent examination of herbarium and fresh material. Additionally, brief propagation notes on both species are provided.

\section{Key to Kadsura species in Singapore}

1a. Intercostal leaf venation often prominent adaxially; androecium $8-11 \mathrm{~mm}$ in diam., 9-11 mm high; gynoecium conical; apocarps 9.5-22(-30) $\times 6.5-14(-17.5)$ $\mathrm{mm}$, sessile 1. K. scandens

1b. Intercostal leaf venation often indistinct adaxially; androecium 4-6 $\mathrm{mm}$ in diam., 4-6 mm high; gynoecium shallowly hemispherical; apocarps $(3.5-) 7-11(-12) \times$ (3.5-)6-10(-12) $\mathrm{mm}$, borne on stipes (1.8-)3-11(-20) mm long

2. K. verrucosa

\section{Taxonomic treatment}

1. Kadsura scandens (Blume) Blume, Fl. Javae Schiz. 9, t. 1 (1830); Miquel, Fl. Ned. Ind. 1(2): 19 (1858); King, J. Asiat. Soc. Bengal, Pt. 2, Nat. Hist. 58(4): 375 (1889); King, Ann. Roy. Bot. Gard. (Calcutta) 3: 221, t. 71 (1891); Ridley, J. Straits Branch Roy. Asiat. Soc. 33: 38 (1900); Backer, Schoolfl. Java 16 (1911); Koorders, Exkursionsfl. Java 2: 242 (1912); Ridley, Fl. Malay Penins. 1: 20, fig. 5 (1922); Smith, Sargentia 7: 199 (1947), p.p.; Backer \& Bakhuizen van den Brink, Fl. Java (Spermatoph.) 1: 99 (1964); Steenis, Mountain Fl. Java t. 29.3 (1972); Keng, Concise Fl. Singapore, vol. 1, Gymn. Dicot. 9 (1990), p.p.; Turner, Gard. Bull. Singapore 45: 212 (1993), p.p.; Saunders, Fl. Males., ser. 1, 13: 198, fig. 1 (1997); Saunders, Gard. Bull. Singapore 48: 238 (1998 ['1996’]), p.p.; Saunders, Syst. Bot. Monogr. 54: 72, fig. 34 (1998); Tan et al. in Davison et al. (eds), Singapore Red Data Book, ed. 2: 225 (2008), p.p.; Chong et al., Checkl. Vasc. Pl. Fl. Singapore 52, 181, 207 (2009), p.p.; Phoon, Fl. Penins. Malaysia, ser. 2, 1: 216 (2010). - Sarcocarpon scandens Blume, Bijdr. Fl. Ned. Ind. 21 (1825). TYPE: [Indonesia], Java, Blume s.n. (lectotype L [L0038277], designated by Saunders, Fl. Males., ser. 1, 13: 199 (1997); probable isolectotypes BM [BM000548435], HBG [HBG-510745], K [K000681704], NY [NY00030333]). - EPITYPE: Indonesia, Java, U[d]jung Kulon Nature Reserve, Mt Pajung, 150 m, 10 December 1964, Kostermans 21837 (epitype K [K001278785], designated here to support the ambiguous lectotype (see notes below); isoepitype L [L0275834]). (Fig. 1-3)

Kadsura cauliflora Blume, Fl. Javae 11, t. 2 (1830); Miquel, Fl. Ned. Ind. 1(2): 19 (1858); Backer, Schoolfl. Java 17 (1911). - TYPE: [Indonesia], Java, [Mt Boerangrang] 'montis Burangrang', Blume s.n. (lectotype: K [K000681703], designated by Smith, Sargentia 7: 200 (1947); probable isolectotypes HBG [HBG-510744], L [L0038273, L0038274, L0038275, L0038276]). 
Schisandra ovalifolia P.Parm., Bull. Sci. France Belgique 27: 237, 312 (1896), as 'Schizandra ovalifolia'. - TYPE: [Indonesia], Sumatra, Ajer Mantjoer, Padang, August 1878, Beccari PS 667 (lectotype K [K000681702], designated by Smith, Sargentia 7: 200 (1947); isolectotypes BM [BM000548434], FI [FI018919], L [L0038272]).

Woody vines. Leaves: lamina papyraceous to coriaceous, elliptic to ovate, (9-)10$15(-21) \times(4.5-) 5-9(-15) \mathrm{cm}$, length:width ratio (1.3-)1.4-2.1(-2.4), apex acute to acuminate, base obtuse to truncate (cuneate in younger leaves), margin entire; secondary veins 4-6(-8), arcuate, intercostal venation often prominent adaxially, prominent abaxially; petiole (7.5-)11.5-30(-48) $\mathrm{mm}$ long, 1.2-2.3(-2.8) $\mathrm{mm}$ in diam. Flowers either borne solitary in axils of leaves (occasionally with secondary flower borne in axil of prophyll) or in axils of fugaceous bracts, occasionally cauliflorous. Tepals 10-18(-24), white, pale yellow or red, outer segments occasionally pale green, tinged red; outermost segment 1.5-3.8 $\times$ 2.0-3.3 mm; innermost 4.3-7.3 $(-10.5) \times$ 2.9-6.2 mm; largest (7.4-)9-16(-18.9) × (4.7-)7-12(-14.3) mm. Male flowers with 24-52 stamens tightly compressed into a globose or ellipsoidal head, androecium 8-11 $\mathrm{mm}$ in diam., 9-11 $\mathrm{mm}$ high, anthers \pm sessile, connectives broad, with dorso-laterally positioned thecae. Female flowers with a conical gynoecium of 50-82(-110) carpels; pseudostigma broad, subpeltate. Fruit with 40-93 apocarps (possibly more); apocarp a berry, obovoid, ripening red or yellow, 9.5-22(-30) $\times 6.5-14(-17.5) \mathrm{mm}$, sessile, apex often beaked. Seeds 1-2 per berry, pyriform, discoid or reniform, (4.5-)5-8.5($10) \times(4-) 5-9(-11) \mathrm{mm}$.

Distribution. Peninsular Malaysia, Sumatra, Java and Bali.

Specimens examined. SINGAPORE: Bajau, 1894, Ridley 6242 (K [K000842046], SING [SING0025842]). Bukit Timah Nature Reserve: Anonymous 6354 (SING [SING0025840]); ibidem, 1894, Ridley s.n. (SING [SING0025839]); near quarry, 27 Oct 1932, Nur 26103 (K [K000842041], SING [SING0025841]); Fern Valley, 15 Oct 2019, Niissalo SING2019-1006 (SING [SING0296254]); Fern Valley, 19 Apr 2021, Chen et al. JH 75 (SING [SING0291118, spirit material SING0323232]); Fern Valley, 30 Apr 2021, Chen et al. JH 80 (SING [SING0291119, spirit material SING0323236]), Chen et al. JH 82 (SING [SING0291120]); Fern Valley, 22 Jun 2021, Chen et al. JH 86 (SING [SING0291122]). Kranji: 1894, Ridley s.n. (SING [SING0025838]). Nee Soon Swamp Forest: road connecting Range 1 and 2, 8 May 2015, Lua et al. SING2015-125 (SING [SING0232273]); ibidem, 17 Dec 2020, Chen et al. JH 70 (SING [SING0291117]).

Notes. Kadsura scandens was originally described as Sarcocarpon scandens (Blume, 1825), but later Blume himself transferred it to the genus Kadsura and, in tandem, described $K$. cauliflora (Blume, 1830). Subsequent authors generally regarded Kadsura cauliflora and $K$. scandens as conspecific owing to the lack of remarkable differences between them. While Saunders (1998a) acknowledged that the type specimen of Kadsura scandens is sterile, he contended that "the lectotype and isotypes of $K$. cauliflora are fertile, with flowers and fruits, and both species were excellently illustrated in Blume's Flora Javae (1830)". However, the name Kadsura scandens can be applied with certainty only if its type material possesses critical characters that can be identified with 


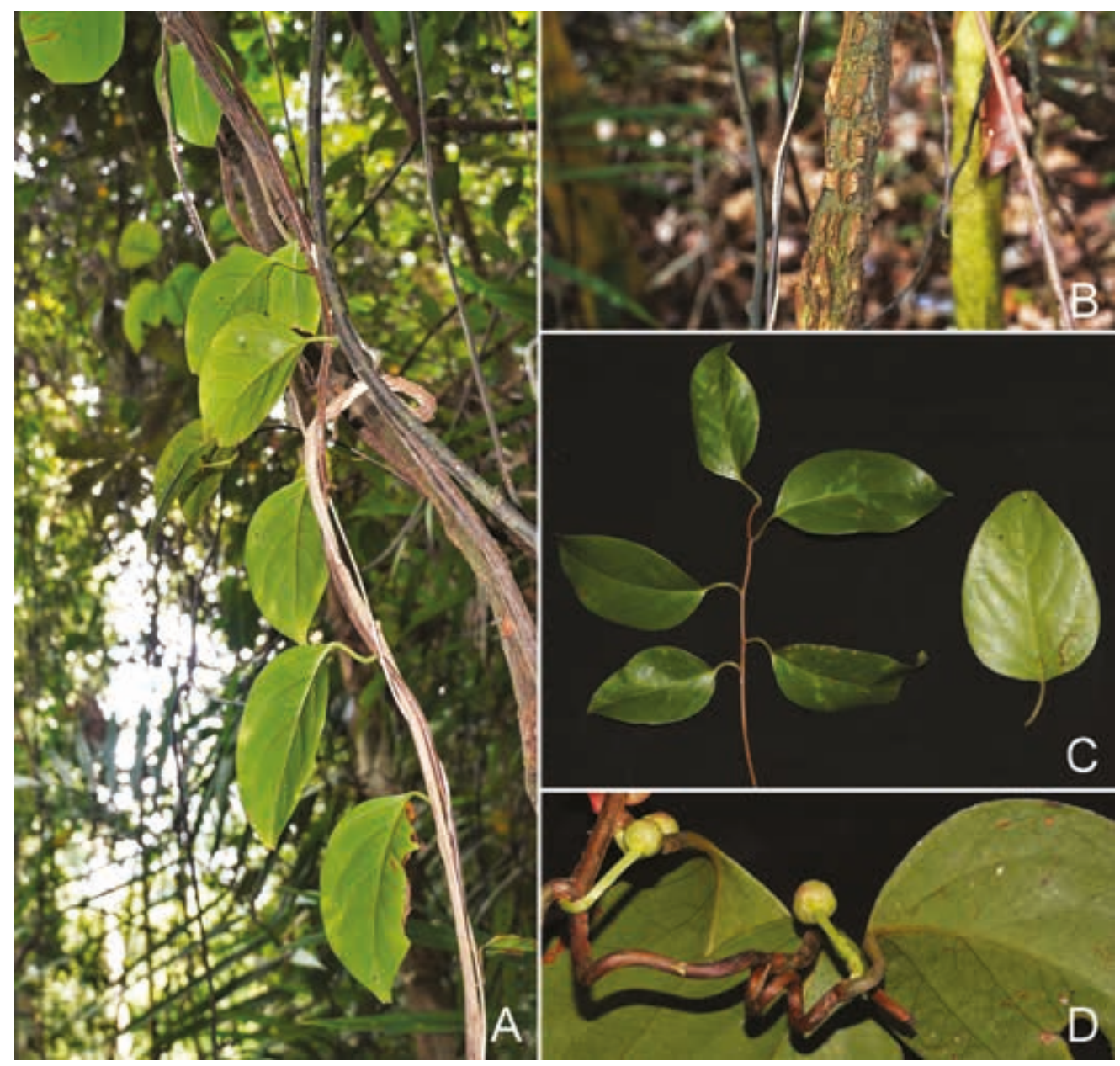

Fig. 1. Vegetative features of Kadsura scandens (Blume) Blume. A. Habit. B. Bark. C. Leaves. D. Twining stem. All from Singapore, Bukit Timah. (Photos: A, B, R.C.J. Lim; C, X.Y. Ng; D, J. Chen)

certainty. The lectotype from L and isolectotypes from $\mathrm{HBG}$ and $\mathrm{K}$ are sterile, while the probable isolectotypes from BM and NY have a few flower buds. Unfortunately, the young flower buds of Kadsura scandens and its most similar species $K$. verrucosa are virtually inseparable. Although several differences in leaf morphology between Kadsura scandens and $K$. verrucosa have been identified in previous treatments, the present study shows a significant overlap in leaf morphology that sometimes renders the identification of sterile material impossible. Saunders (1998a) keyed out the two species in part using the prominence of leaf intercostal venation (prominent adaxially in Kadsura scandens, indistinct adaxially in $K$. verrucosa) while acknowledging that "there is limited support for accepting the distinction between $K$. scandens and $K$. verrucosa based on vegetative characters". However, recent examination of herbarium material suggests that the prominence of adaxial tertiary venation may be inconsistent, 


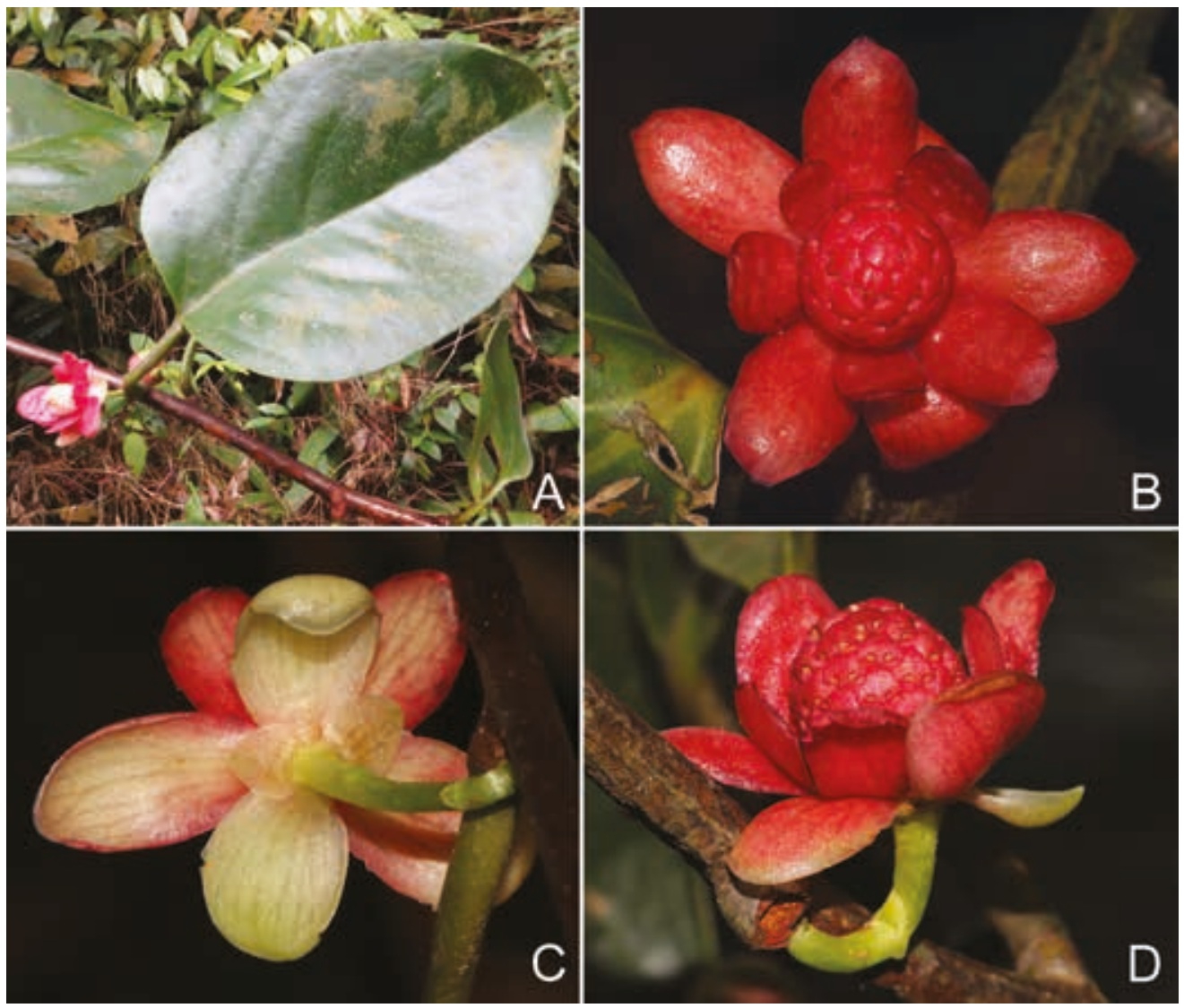

Fig. 2. Male flowers of Kadsura scandens (Blume) Blume. A. Axillary position of flowers. B. Adaxial view. C. Abaxial view. D. Side view showing dorso-laterally positioned thecae. From Singapore; A from Nee Soon, Lua et al. SING2015-125; B, C from Bukit Timah, Chen et al. JH 80; D from Bukit Timah, Chen et al. JH 75. (Photos: A, H.K. Lua; B, C, X.Y. Ng; D, J. Chen)

especially in younger leaves and older material. In addition, the differences in the number, thickness and curvature of secondary veins given in the key by Phoon (2010) are shown to be overlapping in the present study. The existing lectotype of Kadsura scandens from $\mathrm{L}$ is sterile and the only leaf that has the adaxial surface exposed is badly torn. Moreover, the adaxial leaf intercostal venation is faintly visible, somewhat similar to the typical venation in Kadsura verrucosa specimens and unlike the highly prominent venation more commonly encountered in $K$. scandens specimens. Four specimens from other herbaria are here regarded as probable isolectotypes because they are also collected by Blume from Java and labelled as Kadsura scandens. However, the absence of a collection number, date and precise locality cannot exclude the possibility that they belong to a separate gathering. In any case, the adaxial leaf intercostal venation of these probable isolectotypes varies from strongly prominent to slightly distinct, and hence overlaps with Kadsura verrucosa. We therefore conduct the procedure of epitypification to clarify the application of the name Kadsura scandens, 

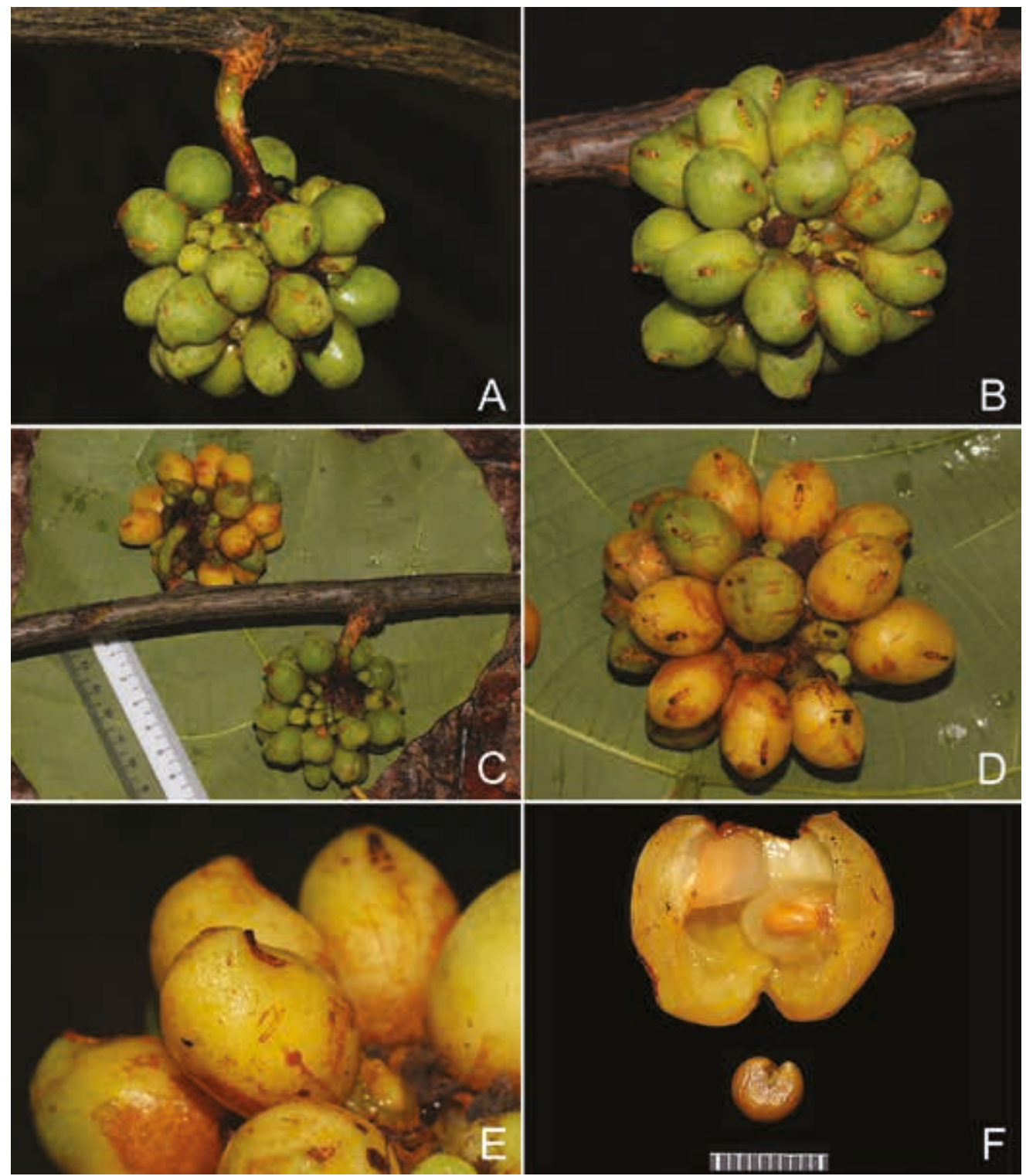

Fig. 3. Fruits of Kadsura scandens (Blume) Blume. A. Side view of developing fruit. B. Adaxial view of developing fruit. C. Abaxial view of developing fruit and mature fruit. D. Adaxial view of mature fruit. E. Close-up of a single apocarp showing the beaked apex and sessile base. F. Sectioned berry and seeds. All from Singapore, Bukit Timah, Chen et al. JH 86. (Photos: A-D, J. Chen; E, F, X.Y. Ng)

according to the recommendations in Lendemer (2020). We select Kostermans 21837 (K) as the epitype of Kadsura scandens because it also originates from Java and possesses distinctive fruit characters (apocarps that are sessile, elongate and relatively large) that readily differentiate it from $K$. verrucosa. 
Parmentier (1896) described Schisandra ovalifolia on page 312 of his Histoire des Magnoliacées. Although a type was not indicated, he cited the specimen Beccari 667 from the Melbourne herbarium on page 237. Beccari's collection is therefore part of the original material, although it cannot be considered a holotype because Parmentier could have used additional uncited duplicates or other specimens for his description. An effective lectotypification had been carried out by Smith (1947) through his indication "O. Beccari 667 (type coll. of Schizandra ovalifolia, K)".

For Kadsura cauliflora, Blume (1830) merely cited a locality "in sylvis montis Burangrang" in his protologue. The type statement "Mt. Boerangrang, C.L. Blume (type coll. of K. cauliflora, K)" in Smith (1947) constitutes the first effective lectotypification of this name, preceding a subsequent lectotype designation by Saunders (1997).

The present study based on examination of herbarium and fresh material has revealed additional differences in the floral morphology of Kadsura scandens and $K$. verrucosa. The former has male flowers with a larger androecium $(8-11 \mathrm{~mm}$ in diam., 9-11 $\mathrm{mm}$ high) and female flowers with a conical gynoecium whereas the latter has male flowers with a smaller androecium (4-6 mm in diam., 4-6 mm high) and female flowers with a shallowly hemispherical gynoecium. The wider range of androecium sizes reported for Kadsura scandens in previous accounts is likely based on measurements of immature male flower buds. It should be noted that the gynoecium shape of both species may change dramatically as the fertilised carpels mature owing to the enlargement and/or elongation of the receptacle. For instance, the receptacle of Kadsura verrucosa may elongate considerably after fertilisation, resulting in a deviation from its original shallowly hemispherical shape. Additionally, the pressing of specimens may cause the conical gynoecium of Kadsura scandens to appear flatter. Therefore, these differences only apply to mature, anthetic flowers, and are best evaluated in fresh or spirit material. The current study also revealed that the berries of Kadsura scandens possess a faint apple-like scent, whereas those of $K$. verrucosa lack any perceptible scent. This may be related to their dispersal syndrome: the sessile, closely appressed, fragrant berries of the former suggest primate dispersal whereas the stalked, odourless berries of the latter lend themselves easily accessible by birds, and hence are indicative of bird dispersal.

2. Kadsura verrucosa (Gagnep.) A.C.Sm., Sargentia 7: 195 (1947); Saunders, F1. Males., ser. 1, 13: 201 (1997); Saunders, Syst. Bot. Monogr. 54: 77 (1998); Phoon, F1. Penins. Malaysia, ser. 2, 1: 217 (2010). - Schisandra verrucosa Gagnep., Notul. Syst. (Paris) 8: 66 (1939), as 'Schizandra verrucosa'. - TYPE: [Vietnam], Tonkin, Binh Lu, 28 March 1936, Poilane 25429 (lectotype A [A00039144], designated by Smith, Sargentia 7: 196 (1947); isolectotypes B [B 10 0278201], K [K000442170], P [P00207186, P00210522, P00210523]). (Fig. 4, 5).

Kadsura cauliflora auct. non Blume: King, J. Asiat. Soc. Bengal, Pt. 2, Nat. Hist. 58(4): 375 (1889); King, Ann. Roy. Bot. Gard. (Calcutta) 3: 222, t. 72 (1891); Ridley, J. Straits Branch Roy. Asiat. Soc. 33: 38 (1900); Ridley, Fl. Malay Penins. 1: 20 (1922). 
Kadsura scandens auct. non (Blume) Blume: Smith, Sargentia 7: 199 (1947), p.p.; Keng, Concise Fl. Singapore, vol. 1, Gymn. Dicot. 9 (1990), p.p.; Turner, Gard. Bull. Singapore 45: 212 (1993), p.p.; Saunders, Gard. Bull. Singapore 48: 238 (1998 ['1996']), p.p.; Tan et al. in Davison et al. (eds), Singapore Red Data Book, ed. 2: 225 (2008), p.p.; Chong et al., Checkl. Vasc. P1. Fl. Singapore 52, 181, 207 (2009), p.p.

Woody vines. Leaves: lamina coriaceous, elliptic to ovate, $(8.5-) 10-15(-21) \times$ 4-12.5(-14) cm, length:width ratio (1.1-)1.4-2.1(-2.8), apex acute to acuminate, base obtuse to truncate, margin entire; secondary veins (4-)5-7(-8), arcuate, intercostal venation often indistinct adaxially, prominent abaxially; petiole (14-)15.5-30(-60) $\mathrm{mm}$ long, (1.1-)1.3-3(-3.7) $\mathrm{mm}$ in diam. Flowers either borne solitary in axils of leaves or in axils of fugaceous bracts, occasionally cauliflorous. Tepals 12-16(-19), yellow, cream or pink; outermost segment $2-3.5 \times 1.8-4.7 \mathrm{~mm}$; innermost 5-8(-16) $\times$ 3.4-6.2(-10.3) mm; largest 11.3-15(-21.5) × 9.6-14(-19.7) $\mathrm{mm}$. Male flowers with 32-57 stamens tightly compressed into a globose or ellipsoidal head, androecium 4-6 $\mathrm{mm}$ in diam., 4-6 mm high, anthers \pm sessile, connectives broad, with dorso-laterally positioned thecae. Female flowers with a shallowly hemispherical gynoecium of (20)44-55 carpels; pseudostigma broad, subpeltate. Fruit with 20-50 apocarps (possibly more); apocarp a berry, globose, ripening red or yellow, $(3.5-) 7-11(-12) \times(3.5-) 6-$ $10(-12) \mathrm{mm}$, borne on stipes, (1.8-)3-11(-20) mm long, apex rounded. Seeds 1-2 per berry, discoid to reniform, 5-8 × 5-6.6(-7.8) $\mathrm{mm}$.

Distribution. Vietnam, Thailand, Peninsular Malaysia, Sumatra and Java.

Specimens examined. SINGAPORE: Botanic Gardens: May 1892, Ridley s.n. (SING [SING0299507]); Gardens Jungle, 1893, Ridley s.n. (SING [SING0001343]). Bukit Timah Nature Reserve: 30 Apr 2018, Lim et al. SING2018-447 (SING [SING0274233]); Main Road, 1 Oct 1973, Hamzah s.n. (SING [SING0025837]); Main Road, 15 May 2019, Niissalo et al. SING2019-446 (SING [SING0295666]); Main Road, 19 Apr 2021, Chen et al. JH 76 (spirit material SING [SING0323233]); Main Road, 30 Apr 2021, Chen et al. JH 81 (spirit material SING [SING0323237]). MacRitchie: near Sime Stream, 1 Jul 2014, Leong et al. MR2014040 (SING [SING0205624]); between Terentang Trail and MacRitchie Nature Trail, c. 100 m south of Island Club Road, 18 Jun 2021, Chen \& Thomas JH 85 (SING [SING0291121]); Rifle Range forest, 14 Jun 2018, Lim \& Ng SING2018-651 (SING [SING0273946]). Nee Soon: roadside, 1 Sep 2013, Ali et al. SING2013-230 (SING [SING0202321]).

Notes. Gagnepain (1939) cited a single gathering Poilane 25429 in his protologue of Schisandra verrucosa, but several duplicates in various herbaria exist. An effective lectotypification was effected by Smith (1947) through his type statement "E. Poilane 25429 (TYPE COLL., A)", rendering a subsequent lectotypification by Saunders (1997) superfluous.

Ridley (1922) misapplied the name Kadsura cauliflora to K. verrucosa, as evidenced from his description "Carpels on pedicels .5 in. long", alluding to the stipitate apocarps that are so far only known from a single Kadsura species, i.e., $K$. verrucosa. Ridley (1900) recorded Kadsura cauliflora from the Gardens Jungle, Bukit 


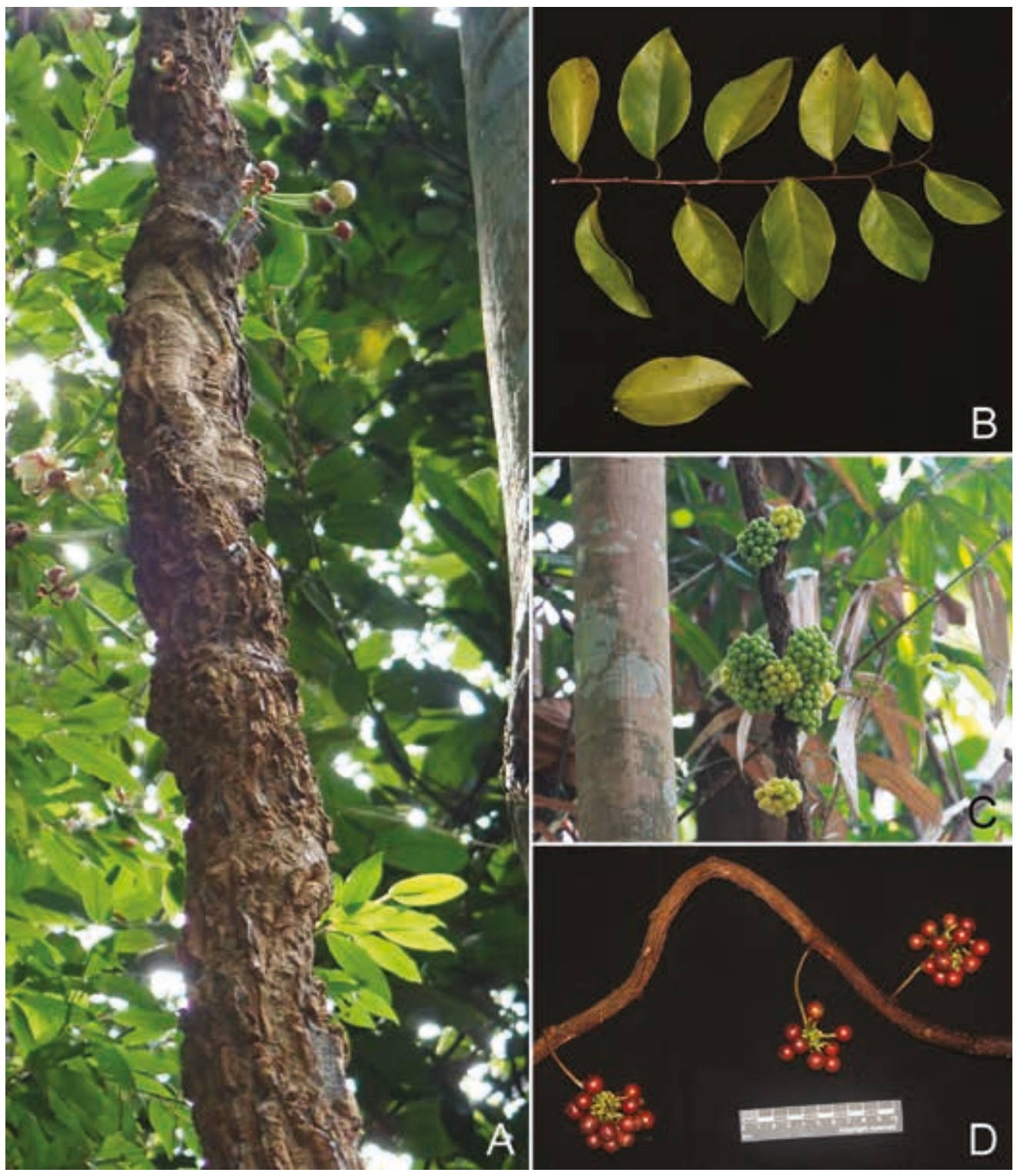

Fig. 4. Kadsura verrucosa (Gagnep.) A.C.Sm. A. Habit and bark. B. Leaves. C. Cauliflorous habit. D. Mature fruits. From Singapore; A, C from Bukit Timah; B from Pasir Panjang Nursery; D from Rifle Range, Lim \& Ng SING2018-651. (Photos: A, H.K. Lua; B-D, X.Y. Ng)

Timah and Kranji in his Flora of Singapore, but later included only the Gardens Jungle as a locality in his Flora of the Malay Peninsula (Ridley, 1922). The Schisandraceae account in the angiosperm flora of Singapore (Saunders, 1998b) cited the "Botanic Gardens' Jungle" as one of the collection localities under Kadsura scandens, but no specimen was cited. In SING, there are two Kadsura verrucosa specimens from the Singapore Botanic Gardens, both collected by Ridley. One of them (SING0299507) 

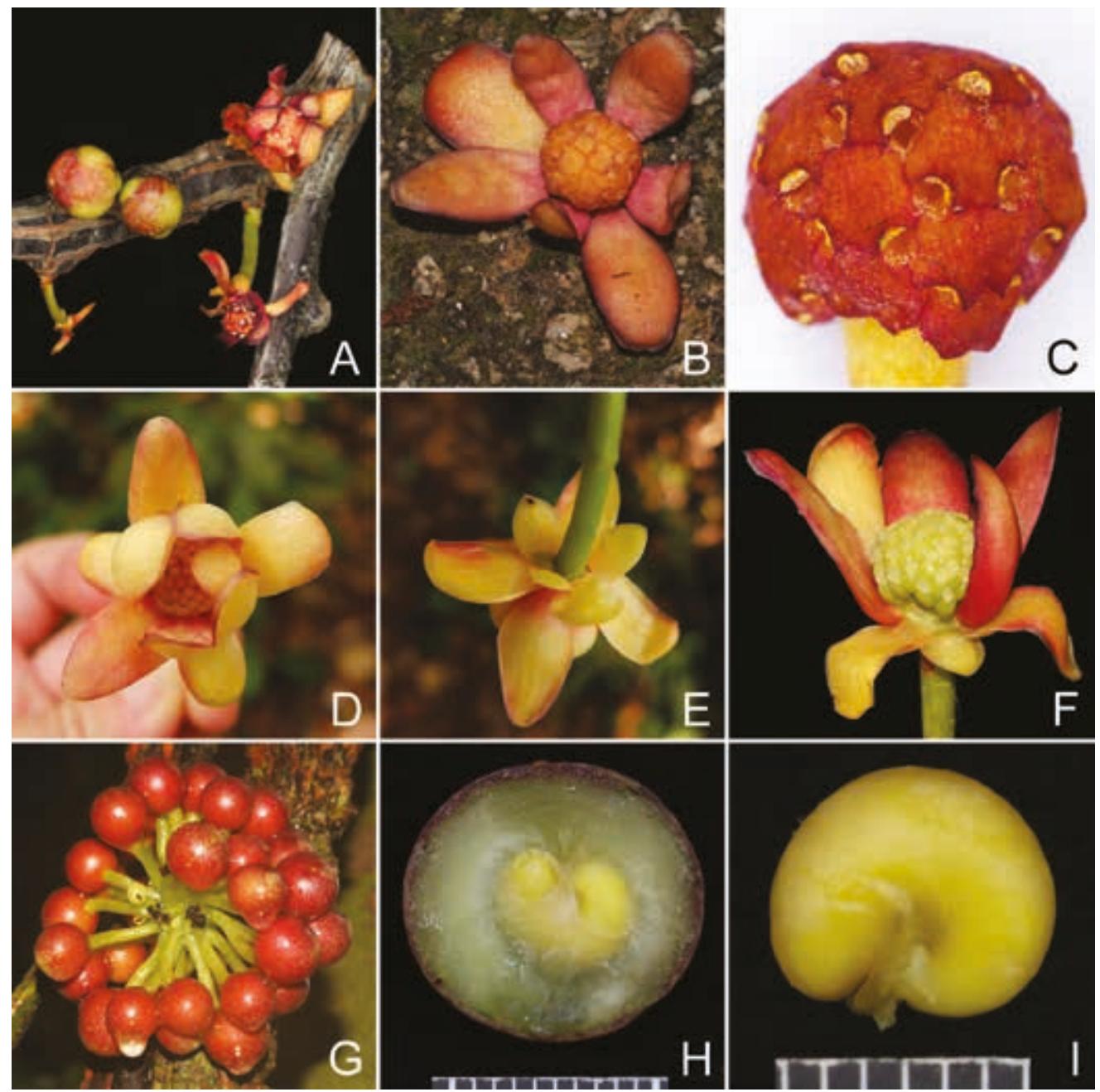

Fig. 5. Kadsura verrucosa (Gagnep.) A.C.Sm. A. Flower buds and male flowers. B. Adaxial view of male flower. C. Close-up of androecium showing dorso-laterally positioned thecae. $\mathbf{D}$. Adaxial view of female flower. E. Abaxial view of female flower. F. Side view of female flower with a few tepals removed in the foreground, showing the shallowly hemispherical gynoecium. G. Fruit showing distinctly stipitate apocarps. H. Sectioned berry. I. Seed. From Singapore; A, C, F from Pasir Panjang Nursery; B from Bukit Timah, Chen et al. JH 81; D, E from Bukit Timah, Lim et al. SING2018-447; G-I from Rifle Range. (Photos: A, F-I, X.Y. Ng; B, C, J. Chen; D, E, P.K.F. Leong)

is a fruiting and flowering specimen that has "Botanic Gardens" and "Kadsura scandens" written by Ridley on its label, and Furtado's annotation "cited in Ridley's Flora as $K$. cauliflora" on the sheet. The other collection is a flowering specimen (SING0001343) that has "Gardens Jungle" and "Kadsura cauliflora" written by Ridley on its label, but with I.H. Burkill's annotation "I like this to be K. scandens" on the sheet. The distinctive stipitate apocarps alluded to in Ridley (1922) is only 

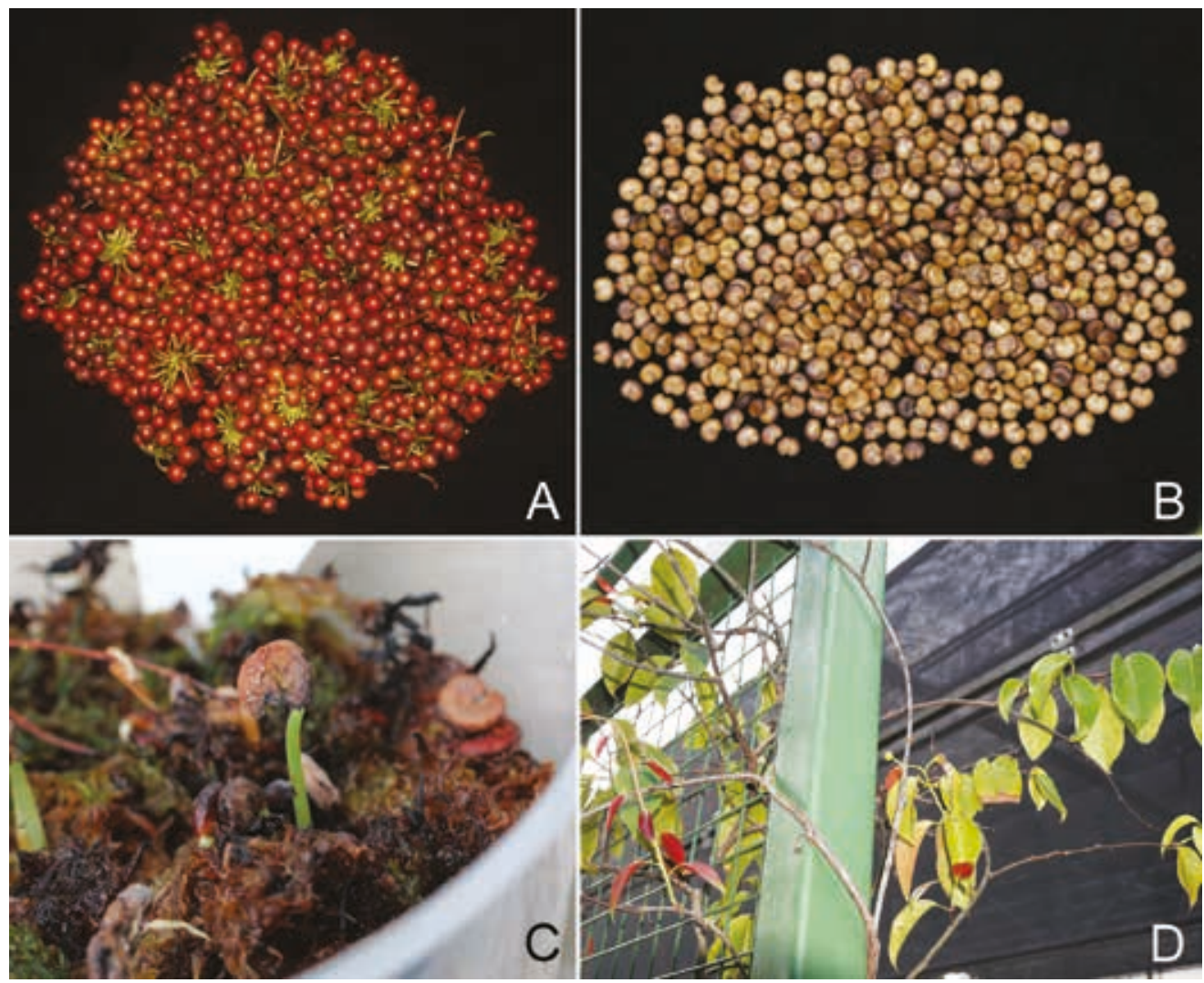

Fig. 6. Propagation of Kadsura verrucosa (Gagnep.) A.C.Sm. A. Collection of mature fruits. B. Cleaned seeds. C. Seedling. D. Young plant cultivated in the Pasir Panjang Nursery. (Photos: A-C, X.Y. Ng; D, R.C.J. Lim)

present in SING0299507; therefore, it is likely to be mislabelled as Kadsura scandens and Ridley's citation of the Gardens Jungle as a locality of $K$. cauliflora may have been based on this specimen as Furtado suggested. Neither specimen was cited in the Kadsura monograph (Saunders, 1998a). Ridley's 1892 specimen [SING0299507] from the "Botanic Gardens" is the oldest fruiting specimen of Kadsura verrucosa; subsequent fruiting specimens were not collected until more than a century later in 2013, after the completion of Saunders' monograph and floristic account.

\section{Propagation notes}

The fruits of Kadsura verrucosa were collected from an individual at Rifle Range forest in June 2018. More than 200 fruits were collected during that fruiting event (Fig. 6). However, only a small number of seeds were found to be viable upon removal of flesh and closer inspection, as most of the seeds were soft and lacked an embryo 
although the outer flesh was dark red and soft, indicating peak ripeness. A germination trial with 15 hard seeds was conducted, and 13 seeds germinated in a media of 1:1 coarse sand and cocopeat over a period of 154 days. This individual was also observed to produce many fruits every three years, as there was another fruiting event in June 2021. No seedlings or older individuals were found in the vicinity of this individual, which could be a result of the low viability of seeds produced. Seeds were collected from the June 2021 fruiting event but the germination rate was disappointing with none of the 40 seeds germinating. Mature individuals from the 2018 fruiting event were observed to be flowering in the nursery in March to April 2021. However, no fruits were observed probably due to the lack of pollinators in the vicinity.

Another fruiting individual of Kadsura verrucosa with orange-red fruits was found off the boardwalk along Petaling Trail in August 2021. Seeds were germinated in three different media: Sphagnum moss, pure coarse sand and a mixture of 1:1 coarse sand and cocopeat. Germination rates were extremely high for all three trials with more than $90 \%$ success rate.

Seeds collected from the Kadsura scandens individual were germinated in a mixture of 1:1 coarse sand and cocopeat in August 2021 with eight seeds germinating out of the 20 planted.

Stem cuttings of Kadsura verrucosa were rooted in the same media of 1:1 coarse sand and cocopeat with the aid of $8 \mathrm{~g} / \mathrm{L}$ IBA (Indole Butyric Acid) rooting gel. There was a success rate of $90 \%$ with more than 48 rooting out of the 53 cuttings. Several stems of Kadsura scandens from the Fern Valley population were observed to be layering on the forest floor with fine roots. They were collected and have successfully established in the nursery. Further propagation efforts will be conducted with the availability of viable seeds and stem cuttings.

ACKNOWLEDGEMENTS. We are grateful to Matti Niissalo, Paul Leong and Daniel Thomas for sharing the localities of Kadsura species. We would also like to thank Seah Wei Wei, Aireen Phang and Choo Le Min for field assistance, Paul Leong, Koh Sin Lan, Lim Weihao and Paul Parusuraman Athen for discussing the distinction between the two Kadsura species, Ian Turner (K), Nicolien Sol (L), Amy Weiss (NY) and Anthony Brach (A) for sending digital images of herbarium specimens, and David Middleton, John McNeill and John Wiersema for advice on nomenclatural matters.

\section{References}

Blume, C.L. (1825). Bijdragen tot de Flora van Nederlandsch Indië. Batavia: Ter Lands Drukkerij.

Blume, C.L. (1830). Flora Javae nec non Insularum Adjacentium. Brussels: J. Frank.

Chong, K.Y., Tan, H.T.W. \& Corlett, R.T. (2009). A Checklist of the Total Vascular Plant Flora of Singapore: Native, Naturalised and Cultivated species. Singapore: Raffles Museum of Biodiversity Research, National University of Singapore. 
Gagnepain, F. (1939). Magnoliacées nouvelles ou litigieuses. Notul. Syst. (Paris) 8: 63-66.

Keng, H. (1990). The Concise Flora of Singapore: Gymnosperms and Dicotyledons. Singapore: Singapore University Press.

King, G. (1889). Materials for a flora of the Malayan Peninsula. J. Asiat. Soc. Bengal, Pt. 2, Nat. Hist. 58: 359-408.

King, G. (1891). The Magnoliaceae of British India. Ann. Roy. Bot. Gard. (Calcutta) 3: $197-$ 223.

Lendemer, J.C. (2020). Epitypes are forever: best practices for an increasingly misused nomenclatural action. Taxon 69: 849-850.

Parmentier, P.E. (1896). Histoire des Magnoliacées. Bull. Sci. France Belgique 27: 159-337.

Phoon, S.N. (2010). Schisandraceae. In: Kiew, R., Chung, R.C.K., Saw, L.G., Soepadmo, E. \& Boyce, P.C. (eds) Flora of Peninsular Malaysia, ser. 2, Seed Plants, vol. 1, pp. 211-217. Malaysia: Forest Research Institute Malaysia.

Ridley, H.N. (1900). The Flora of Singapore. J. Straits Branch Roy. Asiat. Soc. 33: 27-196.

Ridley, H.N. (1922). The Flora of the Malay Peninsula, vol. 1. London: L. Reeve \& Co.

Saunders, R.M.K. (1997). Schisandraceae. In: Kalkman, C., Stevens, P.F., Kirkup, D.W., De Wilde, W.J.J.O. \& Nooteboom, H.P. (eds) Flora Malesiana, ser. 1, Seed Plants, vol. 13, pp. 185-207. Leiden: Rijksherbarium.

Saunders, R.M.K. (1998a). Monograph of Kadsura (Schisandraceae). Syst. Bot. Monogr. 54: $1-106$.

Saunders, R.M.K. (1998b ['1996']). The angiosperm flora of Singapore. Part 4. Schisandraceae. Gard. Bull. Singapore 48: 237-240.

Saunders, R.M.K. (2000). Monograph of Schisandra (Schisandraceae). Syst. Bot. Monogr. 58: $1-146$.

Smith, A.C. (1947). The families Illiciaceae and Schisandraceae. Sargentia 7: 1-224.

Suetsugu, K., Hsu, T.-C., Toma, T., Miyake, T. \& Saunders, R.M.K. (2017). Emended description and resurrection of Kadsura matsudae (Schisandraceae). Phytotaxa 311(3): $255-262$. 